\title{
Acetaminophen Attenuates Obesity- Related Renal Injury Through ER-Mediated Stress Mechanisms
}

\author{
Cuifen Wang ${ }^{a, b}$ Miaozong Wu $u^{a, b, c}$ Ravikumar Arvapallia, Xiaoniu Dai ${ }^{\mathrm{d}}$ \\ Muhammad Mahmood ${ }^{c}$ Henry Driscollc Kevin M. Rice ${ }^{a}$ Eric Blough ${ }^{a, b, c}$

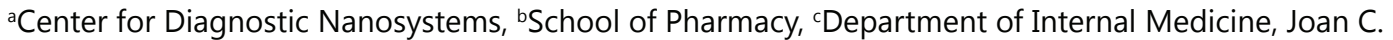 \\ Edwards School of Medicine, Marshall University, Huntington, WV, USA; dMedical School of Southeast \\ University, Nanjing, Jiangsu, China
}

\section{Key Words}

Obesity • Acetaminophen $•$ Kidney $・$ Endoplasmic reticulum stress $・$ Lipotoxicity $・$ Apoptosis

\begin{abstract}
Background/Aims: Obesity is an independent risk factor for the development of kidney disease. The purpose of this study was to determine how obesity may contribute to renal damage and whether acetaminophen ingestion can diminish obesity-associated renal cell injury in the obese Zucker rat model. Methods: Male obese Zucker rats (4 weeks old, $\mathrm{n}=6$ ) were treated with acetaminophen ( $30 \mathrm{mg} / \mathrm{kg}$ body weight / day) for 26 weeks. Age matched obese control $(\mathrm{OC})$, obese vehicle $(\mathrm{OV}, 0.073 \mathrm{~mL} \mathrm{DMSO} / \mathrm{kg} / \mathrm{d}$ ), and lean Zucker rats (LC) were used to determine the effects of treatment and obesity. Results: Compared to lean control rats, renal lipid deposition, expression of the endoplasmic reticulum (ER) stress protein GRP78 and activation of the ER stress-related eIF2 $\alpha$-ATF4-CHOP, caspase 12, and JNK-MAPK signaling pathways were increased in the obese control and obese vehicle rats. These alterations were associated with the elevated renal cell apoptosis and urinary albumin excretion. Acetaminophen treatment decreased renal lipid deposition, ER-stress related signaling, apoptosis and albuminuria. Conclusion: These data suggest that the protective effects of low dose acetaminophen on renal injury are mediated, at least in part, through attenuation of ER stress.
\end{abstract}

Copyright $\odot 2014$ S. Karger AG, Basel

\section{Introduction}

It is estimated that more than two thirds of adults in the United States are overweight or obese [1]. Paralleling this rise in obesity is an increase in the incidence of chronic kidney 


\section{Cellular Physiology and Biochemistry}

Cell Physiol Biochem 2014;33:1139-1148

DOI: $10.1159 / 000358683$

Published onlıne: April 11, 2014

C) 2014 S. Karger AG, Basel

www.karger.com/cpb

disease (CKD) [2-4]. How obesity might increase CKD is not well understood. However, it is well accepted that increased renal lipid levels may play a pivotal role in the pathogenesis of obesity-associated nephropathy. Indeed, recent researches have demonstrated that lipid accumulation can induce functional impairment (lipotoxicity) and cell death (lipoapoptosis) [5, 6]. The mechanism(s) regulating renal lipoapoptosis have not yet been elucidated; however, it has been suggested that the abnormal lipid accumulation can induce endoplasmic reticulum (ER) stress and cellular apoptosis in several tissue types [7-9]. As endoplasmic reticulum plays a critical role in regulating metabolic homeostasis and cellular functions, perturbations of ER homeostasis in pathological conditions such as excess lipid accumulation can lead to abnormal protein translation and folding, also known as unfolded protein response, which if allowed to proceed unchecked can activate apoptotic pathway and result in cell death $[8,9]$.

Acetaminophen (N-acetyl-p-aminophenol, APAP) is a widely used over-the-counter analgesic and antipyretic drug. Previous data has demonstrated that acetaminophen treatment can be effective in attenuating the increases in body fat deposition subsequent to the initiation of a high-fat diet in mice [10-12]. Whether chronic acetaminophen ingestion can function to reduce renal lipid accumulation and lipotoxicity during the development of obesity has, to our knowledge, not been investigated. To address this gap in our understanding, we examined whether acetaminophen ingestion can reduce renal lipid accumulation and lipoapoptosis in the obese Zucker rats and the potential role that ER stress may play in these processes. Our data suggest that acetaminophen administration at $30 \mathrm{mg} / \mathrm{kg} / \mathrm{d}$ can attenuate albuminuria and renal lipotoxicity in the obese Zucker rat, and that these effects are mediated, at least in part, by diminished ER-stress related signaling.

\section{Materials and Methods}

\section{Animal study}

Male obese and lean Zucker rats ( 3 weeks old) were purchased from Charles River Laboratories and housed two per cage under controlled temperature $\left(\sim 22^{\circ} \mathrm{C}\right)$ and humidity $(\sim 50 \%)$ with a 12:12 h light:dark cycle. Food and water were available ad libitum. After a week for environmental acclimation, the obese Zucker rats were randomly assigned into one of three groups ( $\mathrm{n}=6 \mathrm{each}$ ): obese control (OC), obese vehicle (OV, $0.073 \mathrm{~mL}$ DMSO $/ \mathrm{kg} / \mathrm{d}$ ), or obese treated with acetaminophen (OT). Acetaminophen (30mg/kg/d) was dissolved in DMSO and then provided to animals via drinking water for 26 weeks as described previously [13]. Age-matched lean Zucker rats were used as controls ( $\mathrm{LC}, \mathrm{n}=6)$. Animals were euthanized at 30 weeks for the collection of tissues and urine. Urine specimens were centrifuged at $2000 \mathrm{xg}$ for $5 \mathrm{~min}$, and the supernatant was stored at $-80{ }^{\circ} \mathrm{C}$. After removal, kidneys were snap frozen in liquid nitrogen and stored at $-80{ }^{\circ} \mathrm{C}$. All animal procedures were conducted under the Animal Use Review Board of Marshall University using the criteria outlined by the Association for Assessment and Accreditation of Laboratory Animal Care (AAALAC) as described in the Animal Welfare Act (PL89-544, PL91-979, and PL94-279).

\section{Measurement of urinary albumin content}

Urinary albumin concentration was determined using an enzyme immunoassay assay kit purchased from Cayman Chemical (Ann Arbor, Michigan), while urinary creatinine content was measured using a colorimetric assay kit (Cayman Chemical; Ann Arbor, Michigan). Urinary albumin was normalized to creatinine concentration and expressed as micrograms albumin per milligrams creatinine.

\section{Detection of renal lipid accumulation}

Kidneys were sectioned $(8 \mu \mathrm{m})$ using a IEC Minotome Cryostat, fixed with $4 \%$ formaldehyde, and stained with an oil red 0 staining kit (Poly Scientific R\&D Corp, Bay Shore, NY). Images were captured in a blinded manner using an Olympus BX51 light microscope (Olympus America, Melville, NY, USA) at 200× and $400 \times$ magnification.

Determination of renal nuclear DNA fragmentation

Apoptosis was assessed using a transferase-mediated dUTP nick-end labeling (TUNEL) kit (Roche Applied Science, Indianapolis, IN) as described previously [13, 14]. Images were captured using an Olympus 


\section{Cellular Physiology and Biochemistry}

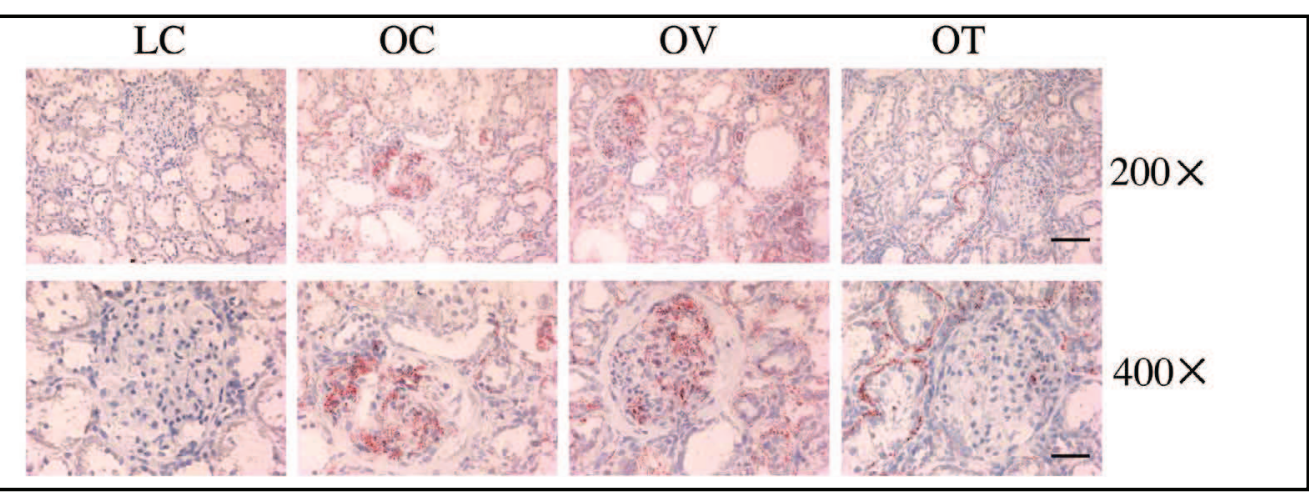

Fig. 1. Chronic acetaminophen treatment is associated with reduced lipid deposition in the kidney of obese Zucker rat. Renal tissue sections were stained with oil red 0 . Representative micrographs were captured at

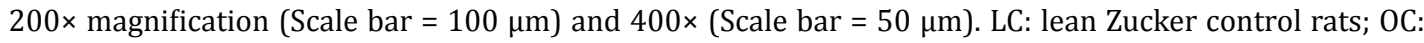
obese Zucker control rats; OV: obese Zucker rats with vehicle (DMSO); OT: obese Zucker rats treated with acetaminophen $(30 \mathrm{mg} / \mathrm{kg} / \mathrm{d})$ for 26 weeks.

BX51 fluorescence microscope (Olympus America, Melville, NY) at 400× magnification. Apoptotic index was expressed as the number of TUNEL-positive nuclei per 100 nuclei (TUNEL+/100 Nuclei).

\section{Immunofluorescence}

Immunofluorescence staining was used to detect the expression and spatial distribution of GRP78 (an ER stress master regulator [15]) and CCAAT-enhancer-binding protein homologous protein (CHOP, a mediator of ER stress-induced apoptosis [16]). Frozen sections were fixed with $4 \%$ formaldehyde, blocked with 5\% BSA, and then incubated with anti-GRP78 (\#ab21685; Abcam, Cambridge, MA) or antiCHOP antibody (\#sc-575; Santa Cruz Biotechnology, Dallas, TX) overnight at $4^{\circ} \mathrm{C}$. After washing, sections were incubated with secondary antibody (fluorescein-labeled goat anti-rabbit IgG; Vector Laboratories, Burlingame, CA) for 60 minutes at room temperature. Images were captured using an Olympus BX51 fluorescence microscope (Olympus America, Melville, NY).

\section{Immunoblotting}

Total protein extracts were prepared and immunoblotting was performed as previously described $[13,17,18]$. Primary antibodies included anti-GRP78 (\#ab21685), anti-CHOP (\#sc-575), anti-phosphoeIF2 $\alpha$ (\#3597S; Cell Signaling Technology (CST), Danvers, MA), anti-eIF2 $\alpha$ (\#9722; CST), anti-ATF4 (\#ab1371; Abcam), anti-caspase 12 (\#ab62484; Abcam), anti-c-Jun N-terminal kinase (JNK, \#9252; CST), anti-phospho-JNK (\#9251S; CST), and anti-glyceraldehyde-3-phosphate dehydrogenase (GAPDH, \#2118; CST). The secondary antibody was horseradish peroxidase-linked anti-rabbit IgG (CST). Protein level was quantified by AlphaView image analysis software and normalized to the amount of GAPDH of the same animal.

\section{Statistical analysis}

Quantitative results were presented as mean \pm standard error of mean (SEM). Statistical significance was determined by analysis of variance followed by the Tukey's test using SigmaStat 3.5. Differences were considered to be significant at $P \leq 0.05$.

\section{Results}

\section{Acetaminophen reduces lipid deposition in the obese kidney}

Oil red 0 staining suggested that lipid deposition was higher in the glomeruli and tubulointerstitium of the obese control (OC) and vehicle treated (OV) animals than that observed in the lean control (LC), while these obesity-associated changes were markedly reduced in acetaminophen-treated (OT) animals (Fig. 1). 


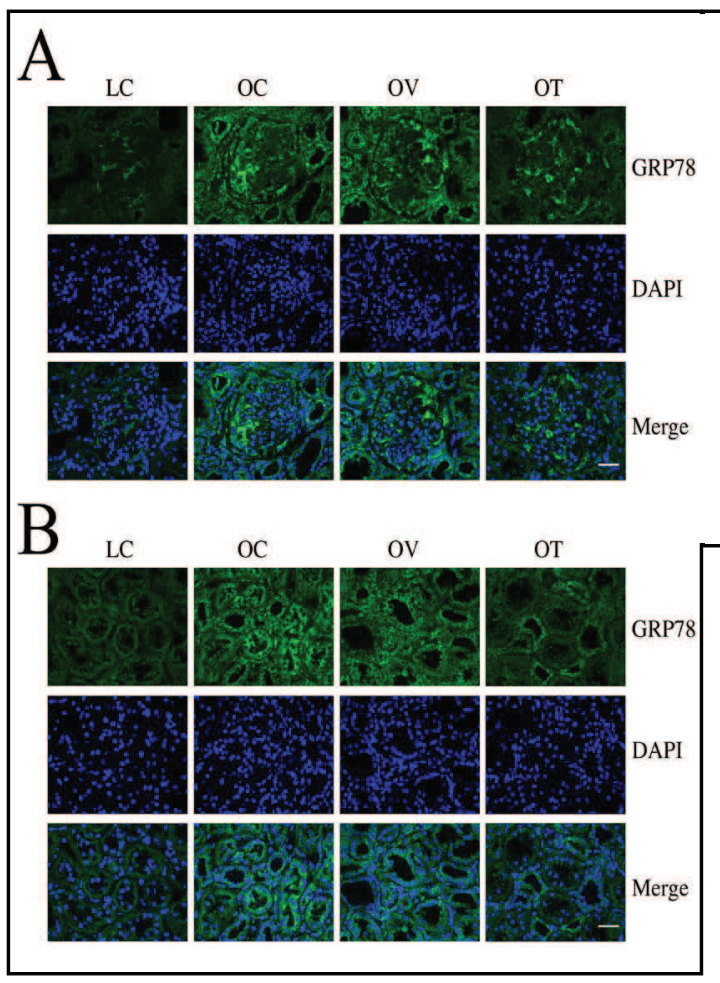

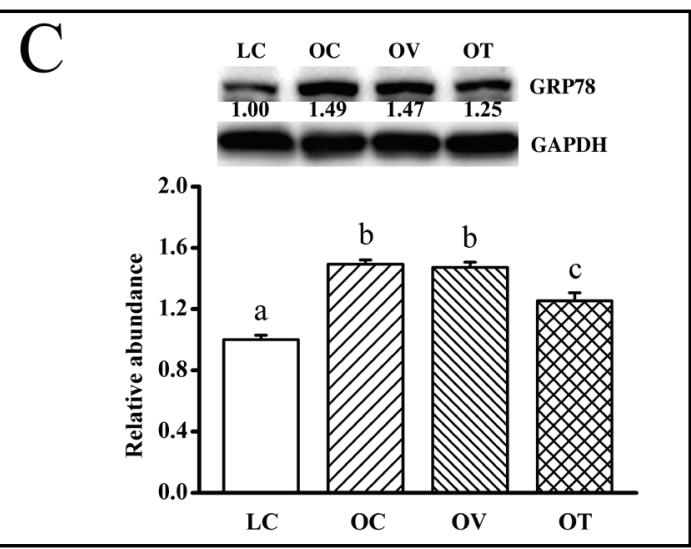

Fig. 2. Acetaminophen treatment decreases renal GRP78 protein levels. A and B. Representative images of golmerular (A) and tubulointerstitial (B) GRP78 immunofluorescence (green signal) were captured at $400 \times$ magnification (Scale bar $=50 \mu \mathrm{m}$, $\mathrm{n}=6$ ). C. GRP78 protein expression was analyzed by immunoblotting and normalized to GAPDH of each animal. Data are expressed as mean \pm SEM $(n=6)$. ab: Groups without the same letter are significantly different $(P \leq 0.05)$.

\section{Acetaminophen decreases GRP78 expression in situ in the obese kidney}

Elevations in ER stress have been implicated in tissues with excess lipid accumulation $[8,9]$ and in the pathogenesis of kidney diseases $[19,20]$. To determine whether the association between changes in renal lipid deposition and acetaminophen treatment were associated with the alteration in renal ER stress, we examined the expression of the ER stress regulator, GRP78 [15]. Compared to that observed in the lean controls, the expression of GRP78 was significantly elevated in both the glomeruli and tubulointerstitium from obese control and vehicle rats and, importantly, attenuated by acetaminophen treatment (Fig. 2A and $B$ ). Taken together, these data suggest that acetaminophen may suppress the activation of renal ER stress in the obese Zucker rat.

\section{Acetaminophen decreases renal eIF2 $\alpha$-ATF4-CHOP pathway in the obese Zucker rat}

It has been suggested that increased ER stress can stimulate CHOP (also known as DNA damage-inducible transcript 3) expression, which plays an important role in inducing apoptosis [21]. Immunofluorescence staining showed that CHOP protein content in both glomeruli and tubulointerstitium was higher in the obese control and vehicle treated rats when compared to that seen in the lean controls while it was visibly decreased following chronic low dosage acetaminophen ingestion (Fig. 3A and B). Immunoblotting analysis further confirmed the diminished expression of CHOP in obese kidney by acetaminophen $(P \leq 0.05$; Fig. 3C).

To further identify the molecular mechanism responsible for altered CHOP expression in obese kidney and the protective effect of acetaminophen, we next examined the regulation of eIF $2 \alpha$ and ATF-4, which are thought to function as the upstream activators of CHOP expression [22]. Compared to lean control animals, the amount of phospho-eIF $2 \alpha$ (p-eIF $2 \alpha$ ) and ATF-4 expression were significantly elevated in obese control and obese vehicle rats $(P \leq 0.05$; Fig.s 3D and E). Consistent with diminished expression of CHOP, the amount of both upstream regulators were attenuated with acetaminophen treatment $(P \leq 0.05$; Fig. $3 \mathrm{D}$ and 3E). There was no difference in the amount of total eIF2 $\alpha$ between the four groups $(\mathrm{P}=0.28$; Fig. 3D). 


\section{Cellular Physiology $\quad$ Cell Physiol Biochem 2014;33:1139-1148 and Biochemistry \begin{tabular}{l|l} 
DOI: 10.1159/000358683 \\
Published onIIne: April I1, 2014 & $\begin{array}{l}\text { O 2014 S. Karger AG, Basel } \\
\text { www.karger.com/cpb }\end{array}$
\end{tabular} \\ Wang et al.: Acetaminophen Attenuates Renal Injury via ER Stress}

Fig. 3. Acetaminophen treatment diminishes eIF2 $\alpha$ ATF4-CHOP pathway. A and B. Representative micrographs $(400 \times)$ of glomerular and tubulointerstitial (B) CHOP immunofluorescence (green signal). Scale bar $=50 \mu \mathrm{m}$. C. Renal CHOP expression. D. Expression of and phosphorylation/ activation of renal eIF2 $\alpha$ protein. E. Expression of renal ATF4 protein. Data are expressed as mean \pm SEM $(\mathrm{n}=$ 6). abc: Groups without the same letter are significantly different $(P \leq 0.05)$.
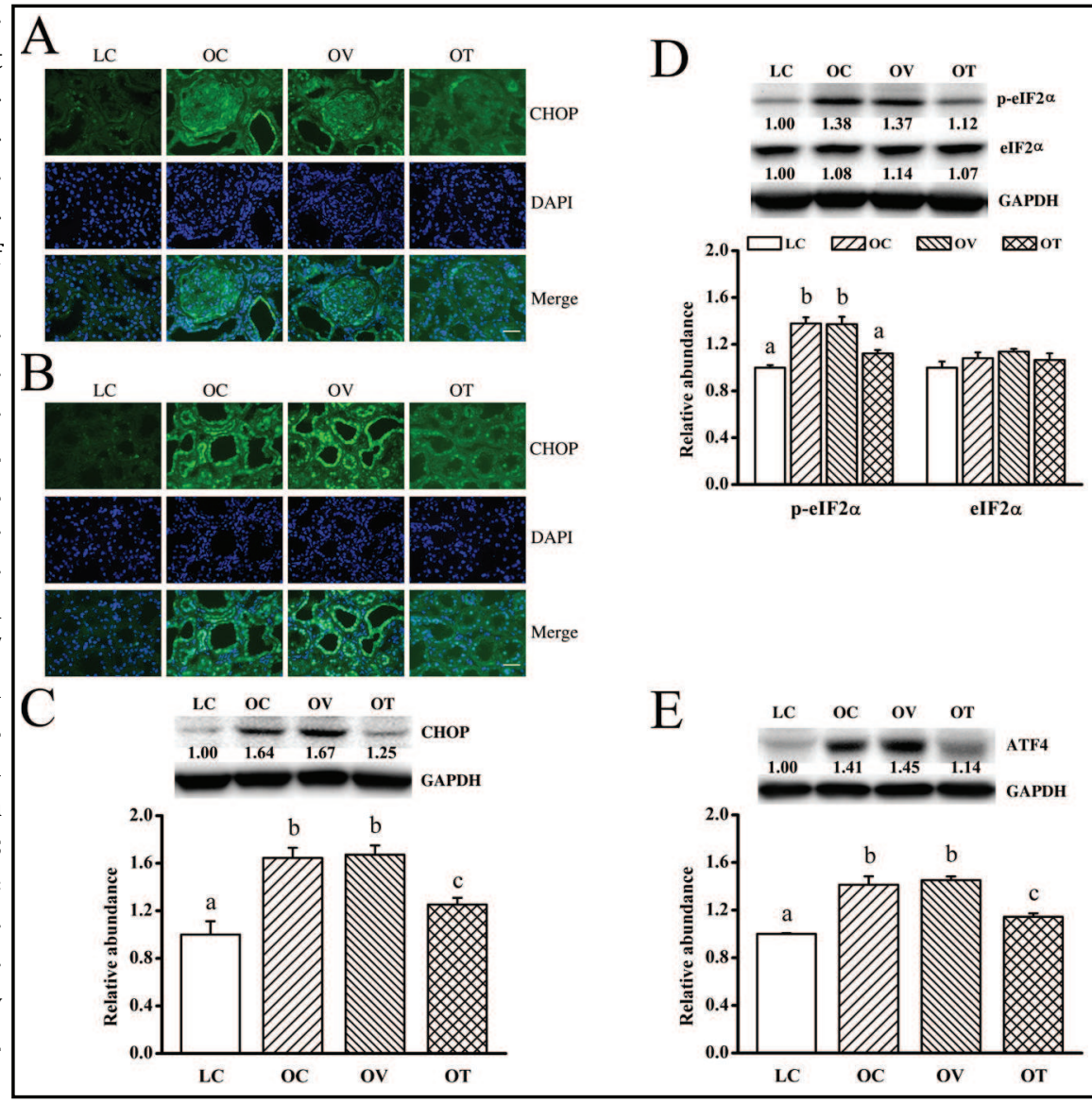

Fig. 4. Acetaminophen treatment suppresses JNK phosphorylation in obese Zucker kidneys. The amount of total and phosphorylated JNK (p-JNK) was analyzed by immunoblotting. Data are expressed as mean \pm SEM $(n=6)$. abc: Groups without the same letter are significantly different $(P \leq 0.05)$.

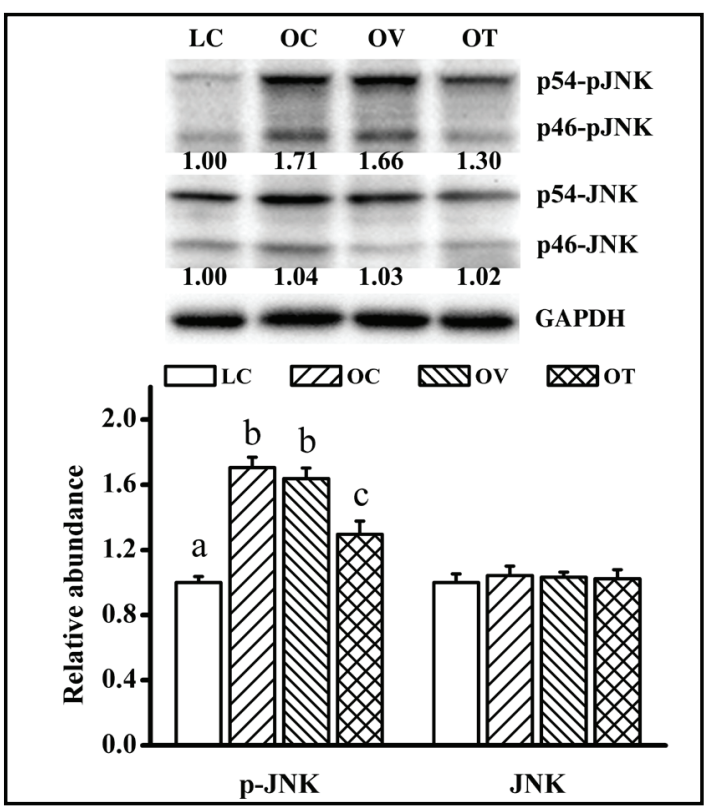

Acetaminophen reduces renal JNK phosphorylation in the obese Zucker rat

Like that observed for eIF2 $\alpha$-ATF4-CHOP pathway, the activation of JNK-MAPK is also thought to be involved in ER stress-induced cell death [16]. Compared with the lean controls, the phosphorylation of JNK (p-JNK) was increased in obese control and vehicle rats $(\mathrm{P} \leq 0.05)$, while it was decreased after acetaminophen ingestion ( $\mathrm{P} \leq 0.05$; Fig. 4). 
A
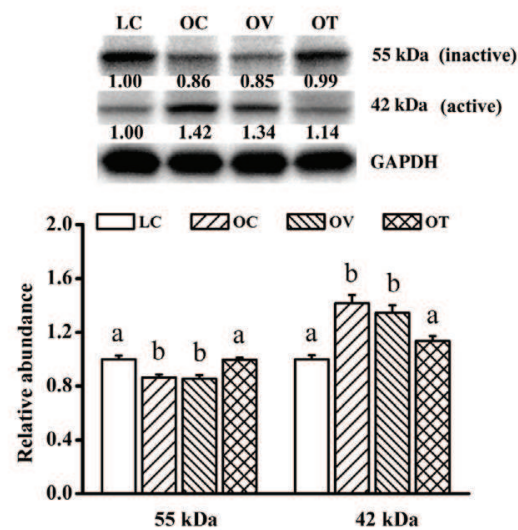

B
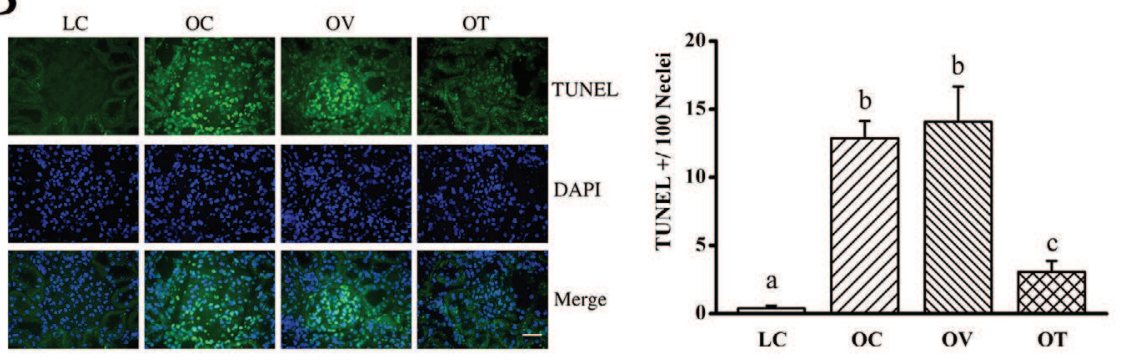

Fig. 5. Acetaminophen treatment decreases caspase 12 activation and apoptosis in the obese Zucker kidney. A. The expression of caspase- 12 protein (full length $55 \mathrm{kDa}$ ) and cleaved caspase-12 (42 kDa fragment; active form) was measured by immunoblotting. B. Renal cell apoptosis in glomerulus was assessed by TUNEL staining. Data are expressed as mean \pm SEM $(n=6)$. abc: Groups without the same letter are significantly different $(P \leq 0.05)$.

Acetaminophen diminishes renal caspase-12 activation and cell apoptosis in the obese Zucker rat

Caspase-12, an ER-resident cysteine protease, is known to be essential for ER stressinduced apoptosis [23]. Compared to the lean control animals, the cleaved product of caspase-12 (active form, 42kDa) was significantly increased in obese control and obese vehicle animals $(\mathrm{P} \leq 0.05)$, while it was diminished following acetaminophen treatment $(\mathrm{P} \leq$ 0.05; Fig. 5A). Paralleling this finding, the amount of full length caspase-12 (inactive form, $55 \mathrm{kDa}$ ) in both $\mathrm{OC}$ and OV rats was significantly less than that of lean control and acetaminophen-treated animals $(\mathrm{P} \leq 0.05$; Fig. $5 \mathrm{~A})$.

To examine whether alterations of eIF2 $\alpha$-ATF4-CHOP, JNK-MAPK and caspase- 12 were associated with renal apoptosis and whether increased apoptosis, if present, can be decreased with acetaminophen treatment, TUNEL staining was used to determine cell apoptosis. The number of TUNEL-positive cells in the glomeruli was higher in the obese control and vehicle animals than that in the lean controls $(P \leq 0.05)$, while it was attenuated with chronic acetaminophen ingestion $(P \leq 0.05$; Fig. 5B). Similar results of altered TUNELpositive cells were found in the tubulointerstitium of obese rats as reported previously [13].

\section{Acetaminophen decreases albuminuria in the obese Zucker rat}

Given our findings of diminished renal cell apoptosis with acetaminophen ingestion, we next examined whether treatment was also associated decreased urinary albumin excretion (albuminuria), an early sign of renal damage [24]. As an estimate of 24-hour urine albumin excretion and to minimize potential differences in urine concentration between animals, 
Fig. 6. Acetaminophen treatment diminishes renal injury in the obese Zucker rat. Albuminuria was determined via the ratio of urinary albumin / creatinine. Data are expressed as mean $\pm \operatorname{SEM}(n=6)$. abc: Groups without the same letter are significantly different $(P \leq 0.05)$.

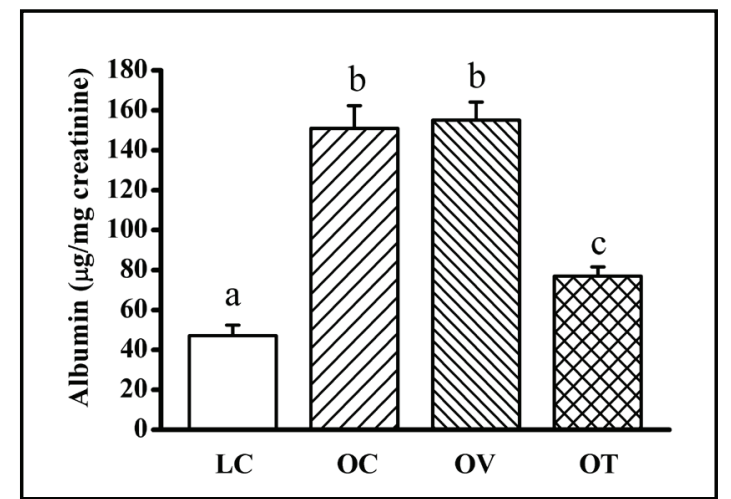

urine albumin content was normalized to urine creatinine concentration and expressed as the ratio of albumin / creatinine, as suggested elsewhere [25]. Compared to the lean controls, urine albumin / creatinine ratio was significantly higher in obese animals (OC and OV), while it was markedly reduced in acetaminophen-treated animals (Fig. 6; $P \leq 0.05$ ).

\section{Discussion}

Increased obesity prevalence and excessive tissue lipid accumulation in obesity have been shown to contribute to the increased kidney dysfunction and renal disease. Using the obese Zucker rat model, we demonstrate that increased renal lipid deposition was associated with increased endoplasmic reticulum stress, cellular apoptosis, and renal damage (albuminuria). In addition, our data suggest that acetaminophen ingestion $(30 \mathrm{mg} / \mathrm{kg} / \mathrm{d}$ for 26 weeks) can attenuate renal lipid accumulation (Fig. 1), renal cell apoptosis (Fig. 5B) and albuminuria (Fig. 6) in the young obese Zucker rat. The renoprotective effects of acetaminophen were associated with the suppression of renal ER stress as suggested by the reduction of GRP78 level (Fig. 2), and the inhibition of apoptotic signaling pathway (diminished eIF2 $\alpha$-ATF4CHOP pathway, and decreased caspase 12 cleavage and JNK phosphorylation, Fig. 3-5A).

Recent studies have demonstrated that obesity is an independent risk factor for both CKD and end-stage renal disease (ESRD) [2-4]. Indeed, it is thought that excess intracellular non-esterified free fatty acid is a contributor to the progression of the renal disease oftentimes associated with obesity [26, 27]. Moreover, FFA overload can also stimulate the synthesis of triglycerides (TGs), very low density lipoprotein (VLDL), and low density lipoprotein (LDL), which may be lipotoxic, especially if the LDL becomes oxidized LDL [2]. In the present study, our analysis of the oil red 0 staining suggested that lipids are dramatically increased in the glomeruli and moderately elevated in the tubulointerstitium of the obese animals (Fig. 1). Oil red $\mathrm{O}$ is a fat-soluble diazo dye that can be used to qualitatively detect the accumulation of not only TGs but also FFA and cholesterol in tissue [28]. Consistent with recent work demonstrating that acetaminophen attenuates high fat diet-induced tissue fat mass [12], here we demonstrated that acetaminophen administration at a low dose $(30 \mathrm{mg} / \mathrm{kg} /$ day $)$ can reduce lipid deposition in the young obese Zucker kidneys. Whether these decreases in lipid deposition are solely responsible for the reduced renal apoptosis seen in the present study or if acetaminophen plays a direct role in preventing cell death is currently unclear and will require additional experimentation.

Previous data has suggested that proteinuria is often associated with increased obesity in humans and animals [29-31]. Consistent with these findings, we also found evidence of significant albuminuria in the young obese Zucker rats used in the present study. In addition, we also noted that acetaminophen treatment can attenuate the extent of albuminuria (Fig. 6). Paralleling these decreases in urine albumin levels we also found that the number of TUNELpositive (apoptotic) cells was increased in the kidneys from both obese control and vehicle animals but diminished with acetaminophen treatment (Fig. 5B). Taken together, these 


\section{Cellular Physiology and Biochemistry}

Cell Physiol Biochem 2014;33:1139-1148

DOI: $10.1159 / 000358683$

Published onlıne: AprilT1, 2014

C) 2014 S. Karger AG, Basel

www.karger.com/cpb

Wang et al.: Acetaminophen Attenuates Renal Injury via ER Stress

Fig. 7. Proposed mechanism of renoprotective effects of acetaminophen in the obese Zucker rat kidney. Excess renal lipid accumulation is associated with increased ER stress, which leads to the increased eIF2 $\alpha$-ATF4-CHOP signaling, elevated cleavage of caspase 12, and activation of JNK signaling that result in increased apoptosis and tissue damage. Acetaminophen reduces renal lipid deposition which in turn reduces ER stress and attenuates renal apoptosis and injury. Red lines represent the effects of obesity (increase/activation), while blue lines represent the protective effects of acetaminophen (decrease/inhibition).

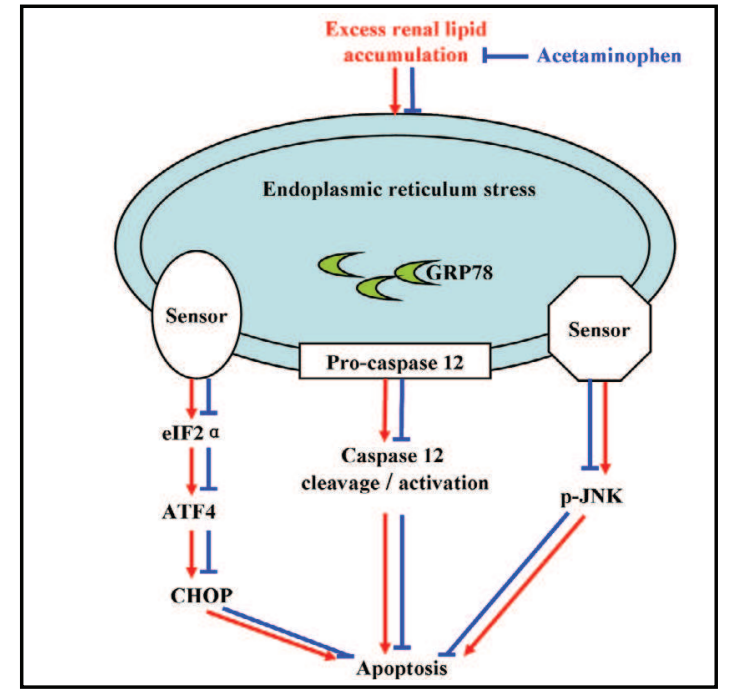

findings suggest that reduced kidney lipid deposition by acetaminophen might function to attenuate obesity-associated renal injuries.

Although the mechanisms involved in renal lipotoxicity have not been fully elucidated, accumulated experimental evidence has suggested that elevations in ER stress may be involved [32]. The ER is a principal site for protein and lipid biosynthesis, protein folding, and calcium storage and signaling. Under conditions of nutrient excess, insulin resistance and diabetes, tissue lipid metabolism can become abnormal causing elevations in ER stress $[9,33]$. To examine the possible mechanism of acetaminophen with renoprotective effect, we investigated the expression and spatial distribution of GRP78, a master regulator of ER stress [15]. Consistent with our findings of reduced renal lipid accumulation and cell injury, we found that renal GRP78 was significantly increased with obesity but diminished with acetaminophen treatment (Fig. 2), suggesting that the renoprotective effect of acetaminophen may be related to its ability to attenuate obesity-associated renal ER stress.

Emerging evidences have suggested that the eIF2 $\alpha$-ATF4-CHOP signaling pathway is involved in FFA-induced apoptosis in human renal proximal tubular cells [8, 34]. Supporting this contention, we found increased levels of eIF2 $\alpha$ phosphorylation (activation) and elevations in the expression of ATF4 and CHOP in the obese kidney, and importantly, that these changes were diminished subsequent to acetaminophen treatment (Fig. 3). Consistent with these data, we also observed other important ER-stress mediators, including JNK phosphorylation and caspase-12 cleavage (activation) [16, 23], were increased in the obese kidneys but diminished following acetaminophen treatment (Fig. 4 and 5).

In summary, the data from this study demonstrate that low dose acetaminophen ingestion $(30 \mathrm{mg} / \mathrm{kg} / \mathrm{d})$ can reduce renal lipid accumulation and the degree of cell injury observed during obesity progression in the young obese Zucker rat. This dosage, if normalized on the basis of body surface area [35], is roughly equivalent to a human dose of approximately $4.9 \mathrm{mg} / \mathrm{kg} / \mathrm{d}$ (or $367.5 \mathrm{mg} / \mathrm{d}$ for a $75-\mathrm{kg}$ person) which suggests that it may be potentially useful for clinical application if long term treatment efficacy and safety can be confirmed. We also demonstrate for the first time that the renoprotective effects of acetaminophen may be mediated, at least in part, by suppressing ER stress and ER stress related apoptosis (Fig. 7).

\section{Acknowledgments}

This work was supported by the Department of Energy grant \#DE-SC0005162. The funders had no role in study design, data collection and analysis, preparation of the manuscript, or decision to publish. The authors would like to acknowledge the support of 


\section{Cellular Physiology and Biochemistry}

Cell Physiol Biochem 2014;33:1139-1148

\begin{tabular}{l|l}
\hline DOI: $10.1159 / 000358683$ & (C) 2014 S. Karger AG, Basel
\end{tabular}

www.karger.com/cpb

Wang et al.: Acetaminophen Attenuates Renal Injury via ER Stress

the Huntington VA Medical Center and the Joan C. Edwards School of Medicine Training

Program in Endocrinology for technical support, laboratory space and equipment.

\section{Disclosure Statement}

All the authors declare that they have no competing interests.

\section{References}

1 Flegal KM, Carroll MD, Kit BK, Ogden CL: Prevalence of obesity and trends in the distribution of body mass index among us adults, 1999-2010. JAMA 2012;307:491-497.

-2 Wahba IM, Mak RH: Obesity and obesity-initiated metabolic syndrome: Mechanistic links to chronic kidney disease. Clin J Am Soc Nephrol 2007;2:550-562.

-3 Crews DC, Plantinga LC, Miller ER $3^{\text {rd }}$, Saran R, Hedgeman E, Saydah SH, Williams DE, Powe NR: Prevalence of chronic kidney disease in persons with undiagnosed or prehypertension in the united states. Hypertension 2010;55:1102-1109.

-4 Ejerblad E, Fored CM, Lindblad P, Fryzek J, McLaughlin JK, Nyren O: Obesity and risk for chronic renal failure. J Am Soc Nephrol 2006;17:1695-1702.

5 Unger RH: Longevity, lipotoxicity and leptin: The adipocyte defense against feasting and famine. Biochimie 2005;87:57-64.

6 Dominguez J, Wu P, Packer CS, Temm C, Kelly KJ: Lipotoxic and inflammatory phenotypes in rats with uncontrolled metabolic syndrome and nephropathy. Am J Physiol Renal Physiol 2007;293:F670-679.

7 Leamy AK, Egnatchik RA, Young JD: Molecular mechanisms and the role of saturated fatty acids in the progression of non-alcoholic fatty liver disease. Prog Lipid Res 2013;52:165-174.

8 Ozcan U, Cao Q Yilmaz E, Lee AH, Iwakoshi NN, Ozdelen E, Tuncman G, Gorgun C, Glimcher LH, Hotamisligil GS: Endoplasmic reticulum stress links obesity, insulin action, and type 2 diabetes. Science 2004;306:457461.

-9 Fu S, Yang L, Li P, Hofmann O, Dicker L, Hide W, Lin X, Watkins SM, Ivanov AR, Hotamisligil GS: Aberrant lipid metabolism disrupts calcium homeostasis causing liver endoplasmic reticulum stress in obesity. Nature 2011;473:528-531.

10 Shertzer HG, Schneider SN, Kendig EL, Clegg DJ, D'Alessio DA, Genter MB: Acetaminophen normalizes glucose homeostasis in mouse models for diabetes. Biochem Pharmacol 2008;75:1402-1410.

-11 Kendig EL, Schneider SN, Clegg DJ, Genter MB, Shertzer HG: Over-the-counter analgesics normalize blood glucose and body composition in mice fed a high fat diet. Biochem Pharmacol 2008;76:216-224.

$\checkmark 12$ Shertzer HG, Kendig EL, Nasrallah HA, Johansson E, Genter MB: Protection from olanzapine-induced metabolic toxicity in mice by acetaminophen and tetrahydroindenoindole. Int J Obes (Lond) 2010;34:970979.

13 Wang C, Blough ER, Arvapalli R, Dai X, Paturi S, Manne N, Addagarla H, Triest WE, Olajide O, Wu M: Metabolic syndrome-induced tubulointerstitial injury: Role of oxidative stress and preventive effects of acetaminophen. Free Radic Biol Med 2013;65:1417-1426.

14 Wang Y, Wu M, Al-Rousan R, Liu H, Fannin J, Paturi S, Arvapalli RK, Katta A, Kakarla SK, Rice KM, Triest WE, Blough ER: Iron-induced cardiac damage: Role of apoptosis and deferasirox intervention. J Pharmacol Exp Ther 2011;336:56-63.

15 Zhang K, Kaufman RJ: Signaling the unfolded protein response from the endoplasmic reticulum. J Biol Chem 2004;279:25935-25938.

-16 Szegezdi E, Logue SE, Gorman AM, Samali A: Mediators of endoplasmic reticulum stress-induced apoptosis. EMBO Rep 2006;7:880-885.

17 Wu M, Liu H, Fannin J, Katta A, Wang Y, Arvapalli RK, Paturi S, Karkala SK, Rice KM, Blough ER: Acetaminophen improves protein translational signaling in aged skeletal muscle. Rejuvenation Res 2010;13:571-579. 


\section{Cellular Physiology and Biochemistry}

Cell Physiol Biochem 2014;33:1139-1148

\begin{tabular}{l|l}
\hline DOI: $10.1159 / 000358683$ & (c) 2014 S. Karger AG, Basel
\end{tabular}
www.karger.com/cpb

Wang et al.: Acetaminophen Attenuates Renal Injury via ER Stress

18 Wu M, Katta A, Gadde MK, Liu H, Kakarla SK, Fannin J, Paturi S, Arvapalli RK, Rice KM, Wang Y, Blough ER: Aging-associated dysfunction of akt/protein kinase b: S-nitrosylation and acetaminophen intervention. PLoS One 2009;4:e6430.

19 Dickhout JG, Carlisle RE, Austin RC: Interrelationship between cardiac hypertrophy, heart failure, and chronic kidney disease: Endoplasmic reticulum stress as a mediator of pathogenesis. Circ Res 2011;108:629-642.

20 Cunard R, Sharma K: The endoplasmic reticulum stress response and diabetic kidney disease. Am J Physiol Renal Physiol 2011;300:F1054-1061.

-21 van der Kallen CJ, van Greevenbroek MM, Stehouwer CD, Schalkwijk CG: Endoplasmic reticulum stressinduced apoptosis in the development of diabetes: Is there a role for adipose tissue and liver? Apoptosis 2009;14:1424-1434.

-22 Han J, Back SH, Hur J, Lin YH, Gildersleeve R, Shan J, Yuan CL, Krokowski D, Wang S, Hatzoglou M, Kilberg MS, Sartor MA, Kaufman RJ: Er-stress-induced transcriptional regulation increases protein synthesis leading to cell death. Nat Cell Biol 2013;15:481-490.

23 Yoneda T, Imaizumi K, Oono K, Yui D, Gomi F, Katayama T, Tohyama M: Activation of caspase-12, an endoplastic reticulum (er) resident caspase, through tumor necrosis factor receptor-associated factor 2-dependent mechanism in response to the er stress. J Biol Chem 2001;276:13935-13940.

24 Mathew AV, Okada S, Sharma K: Obesity related kidney disease. Curr Diabetes Rev 2011;7:41-49.

-25 National Kidney Foundation: K/doqi clinical practice guidelines for chronic kidney disease: Evaluation, classification, and stratification. Am J Kidney Dis 2002;39:S1-266.

-26 Howard S, Bottino C, Brooke S, Cheng E, Giffard RG, Sapolsky R: Neuroprotective effects of bcl-2 overexpression in hippocampal cultures: Interactions with pathways of oxidative damage. J Neurochem 2002;83:914-923.

27 Abrass CK: Cellular lipid metabolism and the role of lipids in progressive renal disease. Am J Nephrol 2004;24:46-53.

28 Mehlem A, Hagberg CE, Muhl L, Eriksson U, Falkevall A: Imaging of neutral lipids by oil red o for analyzing the metabolic status in health and disease. Nat Protoc 2013;8:1149-1154.

-29 Kambham N, Markowitz GS, Valeri AM, Lin J, D'Agati VD: Obesity-related glomerulopathy: An emerging epidemic. Kidney Int 2001;59:1498-1509.

-30 Boini KM, Zhang C, Xia M, Poklis JL, Li PL: Role of sphingolipid mediator ceramide in obesity and renal injury in mice fed a high-fat diet. J Pharmacol Exp Ther 2010;334:839-846.

-31 Ebenezer PJ, Mariappan N, Elks CM, Haque M, Francis J: Diet-induced renal changes in zucker rats are ameliorated by the superoxide dismutase mimetic tempol. Obesity (Silver Spring) 2009;17:1994-2002.

-32 Katsoulieris E, Mabley JG, Samai M, Sharpe MA, Green IC, Chatterjee PK: Lipotoxicity in renal proximal tubular cells: Relationship between endoplasmic reticulum stress and oxidative stress pathways. Free Radic Biol Med 2010;48:1654-1662.

33 Hotamisligil GS: Endoplasmic reticulum stress and the inflammatory basis of metabolic disease. Cell 2010;140:900-917.

-34 Ozcan U, Yilmaz E, Ozcan L, Furuhashi M, Vaillancourt E, Smith RO, Gorgun CZ, Hotamisligil GS: Chemical chaperones reduce er stress and restore glucose homeostasis in a mouse model of type 2 diabetes. Science 2006;313:1137-1140.

-35 Reagan-Shaw S, Nihal M, Ahmad N: Dose translation from animal to human studies revisited. FASEB J 2008;22:659-661. 